\title{
Time Management and Academic Stress in Lima University Students
}

\author{
Yanina Gallardo-Lolandes ${ }^{1}$, Noel Alcas-Zapata ${ }^{1}$, Jessica Elizabeth Acevedo Flores ${ }^{2} \&$ Yolvi Ocaña-Fernández ${ }^{2}$ \\ ${ }^{1}$ Universidad César Vallejo, Perú \\ ${ }^{2}$ Universidad Privada San Juan Bautista, Perú \\ Correspondence: Yolvi Ocaña-Fernández, Universidad Privada San Juan Bautista, Perú.
}

Received: August 20, 2020

Accepted: October 15, 2020

Online Published: November 2, 2020

doi:10.5430/ijhe.v9n9p32

URL: https://doi.org/10.5430/ijhe.v9n9p32

\begin{abstract}
In recent decades, the increase in stress levels of university students has been seen as a serious threat. Due to this problem, the present investigation has been focused on studying how time management is linked to academic stress in university students. This research study of a basic/substantive non-experimental type and correlational level has been developed under a quantitative approach with a cross section. The sample consisted of 328 students of both genders, selected from a public university in the city of Lima. Two standardized tools were adapted for data collection. Two questionnaires were also applied: time management and academic stress. The results showed that there was an inverse correlation between time management and academic stress (Spearman's Rho $=.413$ ), as well as for the dimensions of academic stress: stressors (- .405), symptoms $(-, 387)$ and coping (, 286). It was concluded that the inverse relationships between the parameters studied will be reflected in the values obtained. Furthermore, possible measures to mitigate the casuistry around academic stress are also discussed.
\end{abstract}

Keywords: time management, academic stress, stressors, time organization

\section{Introduction}

Higher education is a stressful period in the lives of students due to various reasons such as living away from families, a heavy curriculum or ineffectiveness in higher education programs (Bhujade, 2017). From the moment an individual enters college, he or she is faced with various demands, especially academic demands, which will demand effort and sacrifice. The university stage involves challenges, goals, and responsibilities that must be overcome and achieved over the years; all of this involves submitting to a type of anxiety defined as stress. Adolescents and young people are particularly vulnerable to problems associated with academic stress since transitions occur at individual and social levels; therefore, it is therefore imperative to understand the sources and impact of academic stress in order to design appropriate and efficient intervention strategies (Reddy, Menon and Thattil, 2018).

According to what Quiliano and Quiliano (2020) have reported, on a universal scale, 14\% of youth suicides were related to academic stress; in addition, in the United Kingdom, a student commits suicide every four days, being the first cause of death for individuals under 34 years old. Also, the aforementioned authors pointed out that in North America, suicide is considered as the second cause of death among university students and $40 \%$ of them showed serious depression. The writers also reported that in Mexico, suicide is the third cause of death among the population in the age group between 15 and 24. Academic stress has been identified as the main cause in these alarming figures (Reddy et al., 2018).

According to estimates by Ribeiro, Mussi, Pires, Silva, Macedo and Santos (2020), in different cities of the planet, one out of every four people suffers from serious stress problems; moreover, it has been estimated that near $50 \%$ of individuals suffer from some equivalent mental disorder. Stress has become part of students' academic lives due to the various internal and external expectations put on their shoulders (Reddy et al., 2018).

Bhujade's (2017) literature review briefly described the research developed over the past three decades, especially regarding stress, anxiety, and depression; focusing on stress problems. In this regard, he emphasized how counseling would help students with emotional problems and also suggested preventive measures that universities should follow such as establishing counseling centers for students, raising awareness among them for seeking help at these centers. He also suggested, among other immediate responses to the problem, the possibility of designing a mandatory 
mentor-apprentice program in all universities, as well as organizing student health committees in each university with mental health professionals as members. Finally he also suggested developing both regular seminars and workshops for university professors and students on various topics about psychological problems and their coping mechanisms.

On the other hand, it should be noted that the dilemmas of academic life are increased due to the demands to fulfill a certain academic program associated with a certain curriculum and, on top of that, the goal of obtaining high grades is also paramount for students. All this generates stress in their academic life mainly because of a deficient or null perception of mechanisms to manage time during university life. Students are faced with an onerous responsibility to organize their study time from their personal and/or social activities.

According to what Barraza (2007) has stated, regarding the university context, enrollment, retention and completion are often considered as learning experiences usually accompanied by periods of academic stress, a topic described as an organic-physiological process, of an adaptive nature, essentially psychological. In addition to the aforementioned ideas, it is necessary to take into account that students will go through periods of anxiety related to academic stress, and if they have not had a good time management of their activities, they will not be able to have an adequate control of these activities, nor will they be able to identify those that are more important to materialize their goals, thus generating a marked increase in academic stress (García, Hernández, Chávez, Och, Cocom y García, 2019).

On the other hand, Castro, Valenzuela Hinojosa and Piscoche (2019) determined that odontology students at San Marcos University suffered from a moderate episode of academic stress due to the level of demand of the college in question, in addition to reporting moderate levels of emotional exhaustion as a result of clinical demands and that of a number of subjects. Regarding local circumstances, the study by Evaristo and Chein (2015) was applied to students of the same specialty. Similarly, the study by Celis, Bustamante, Cabrera, Cabrera, Alarcón and Monge (2001) indicated that students of the specialty of Human Medicine presented stress cases of significant levels.

For the last few years stress has been considered as a growing threat, especially in those educational institutions that are considered to be the most demanding. (Benjamín, 1992). On the other hand, the academic pressure associated with new curricular modifications tends to contribute directly or indirectly to the levels of perception of academic stress (Aldana, Isea and Colina, 2020), a fact that will lead to problems in time organization, thus generating serious difficulties for the fulfillment of academic activities. In this regard, Barraza (2006) stated that if a student does not know how to calculate his or her time in with certain order and above all discipline, he or she will experience a series of negative conditions, which will be reflected in low grades, diminishing his or her performance and leading to states of frustration.

Previous international research on time management and its relationship with procrastination; determined the inverse relationship in three components such as responsibility/cordiality/extraversion at moderate levels (Calderon, Gustems, Calderon and Pujol, 2020); likewise, scientific rigor demonstrates the existence of a strong level relationship (Quiroz, 2019).

Previous research on stress associated with emotional intelligence using the Bar-On and SISCO inventories revealed there is a strong association between both variables in populations of young health science students (Quiliano and Quiliano, 2020). Similar results were obtained by Aldana et al. (2020) in measuring stress when students earn their degree. Other studies on Medicine students by means of the SISCO test demonstrated the existence of significant levels of stress when they are submitted to examinations (stressors), generating an impact on the quality of sleep as well as anxiety conditions (Otero, Carriazo, Oliver, Lacayo, Torres and Pájaro, 2020). On the other hand, Ribeiro et al. (2020) pointed out that stress was strongly associated to professional communication, training and environment, contributing directly on performance. Similarly, García, Pérez and Hinojosa (2004) showed that the high degree of stress generated on graduating as a doctor entails the effects of addictions and certain suicidal thinking tendencies.

In order to evaluate aspects related to time management, researchers such as Sagredo, Bizama and Careaga (2020); Herrero, Perello and Ribes (2019); Calderón and Gustmen (2019) considered orienting this parameter towards specific ends, specifically in the academic or labor field. It is also worth noting what was stated by Nadinloyi, Hajloo, Garamaleki and Sadeghi (2013), who confirm that few students manage their academic time favorably. Therefore, it is important to emphasize that an inadequate time management is not always related to the lack of capacity or knowledge. Assuming this premise, the present research focused on the following problem: How does time management affect academic stress in university students in a public university in Lima? Likewise, the general objective declared was to determine the relationship between time management and academic stress in university students at a public university in Lima. 


\section{Theoretical Aspects}

\subsection{Time Management}

According to Sagredo et al. (2020), time management has been defined in various ways for research purposes, although these approaches converge on a central idea that lies in the completion of tasks or activities in a given time, obtaining quality results, through procedures such as planning, organization or prioritization. On the other hand, Herrero, Perello and Ribes (2019) explained that time management is a process by which defined goals or objectives are established, determining the tools that favor time management, keeping in mind the time available and verifying the use that is given to time; that is, the perception of control that the individual has over the use of time.

According to Marcén and Martínez (2012), it is necessary to indicate that university students are willing to comply with their obligations and, therefore, with the demands of their respective academic programs; but, at the same time, they present the inconvenience of having inadequate time management, a fact that limits their achievements. Time should be considered one of the most important resources in university life. Likewise, they affirm that if time is properly controlled, it will be used to its fullest extent getting the most of it for several resources.

According to García et al. (2004), time management is conceived as a series of processes that are executed in order to achieve established objectives. The benefits of time management tend to reduce situations of procrastination among students, attenuate stress levels; it also allows them to enjoy free time and regulate their performance in learning (Nadinloyi et al., 2013 and Zimmerman and Martinez, 1990) due to an effectively established study schedule (Broc, 2011) that must be linked to aspects such as creativity, motivation, control and use of resources. According to Marcén and Martínez (2012), a use of time distributed according to the needs and priorities of the student reduces waste and optimizes its use, guaranteeing academic success.

To establish the dimensions referring to time management, Roblero (2020) validated an instrument in which four dimensions are considered: (1) 'objectives and priorities', which refers to the establishment of the individual's life project, as well as the objectives to be achieved in long, medium and short term, thus success can be achieved through defined and well planned activities; (2) 'management tools', a set of planned activities that the individual will use to achieve his goals, thus avoiding the generation of possible stress due to poor time management. Here the important thing is to take into account that, within the various activities, we must consider rest and recreation, (3) 'stress generator' is related to the preference for disorganization, an aspect that is contrary to proper planning of activities and that, by default, tends to develop procrastination in people, i.e. leaving everything till the last minute, conditioning it to the symptoms of stress crisis, and (4) 'perception of control', which allows the management of stress at appropriate levels, avoiding possible crisis situations.

\subsection{Academic Stress}

For a long time, people assumed that the student population was the least affected by any type of stress or problem (Reddy et al., 2018). University students often face different stressful situations and concerns: the first contact with the university, freedom to organize schedules, choice of the title of teacher, very selective fields, among others (Saleh, Camart and Romo, 2017). The psychological distress of students is reflected in various forms, including depression, anxiety, stress and sleep disorders (Milojevich and Lukowski, 2016). According to Gregory, Buysse, Willis, Rijsdijk, Maughan, Rowe, Cartwright, Barclay, and Eley (2011), the college years are a period of vulnerability when considering sleep and mental health issues. According to these researchers, sleep problems tend to worsen over time in undergraduates, a finding that is troubling because even the time-limited experience of major sleep problems is associated with reduced mental health outcomes.

Stress is assumed as a set of physiological answers facing some nonconventional situation; stress adapts the organism towards action, that is why in general terms, it must be considered as a biological mechanism and some kind of state of alert for the survival in front of manifestations of fear, anxiety and, in diverse occasions, pathological elements that could unchain equivalent nervous or depressive pathologies (Garcia et al, 2019). According to Bhujade (2017), poor psychological well-being is sometimes associated with physical disorders and may also be associated with the broader concept of "stress", which involves all aspects of life's difficulties, including psychological distress. Similarly, the cited author noted that each student handles the same stress differently.

According to Bhujade (2017), depression, anxiety, and academic stress among college students must be of concern. In this regard, the cited researcher mentioned that every nation invests a lot of money in education; however, a research survey on university students' reports showed that between 10 and $20 \%$ of the student population suffers from psychological problems (stress, anxiety and depression). 
According to Sagredo, Bizama and Careaga (2020), the levels of stress associated with academic activity could be attenuated if time management were used as a tool in such situations, since it would allow academic predicaments to be reduced by generating an improvement in academic efficiency and productivity. In this regard, Calderon and Gustmen (2019) indicated that the organization of student time is part of the culture in countries such as Spain, Germany, China and Japan, being the cultural seal of its citizens, being present in each and every one of their daily obligations. Likewise, in the research carried out in South Korea, Park, Park and Kim (2018) determined that the social support factor and the academic stress factor of university students had a statistically significant influence on university adjustment; they also estimated that the academic stress factor had partial mediating effects on the relationship between the social support factor and university adjustment. These findings illustrated how social support played a buffer role in the face of academic stress, generating college student adjustment.

On the other hand, Zhang and Zheng (2017) stated that Chinese university students are overwhelmed by high academic stress because they will have to face increasing competition in the labor market and academic excellence as a social norm in Asian culture. Because of this context, they are prone to chronic exposure to stress that could negatively influence mental health; therefore, academic stress in particular could lead to negative emotions without adequate and timely coping. Given this context, they conclude that, given the increasing levels of mental health problems among Chinese college students, it was important to understand how academic stress and participation in leisure activities affect emotional well-being on a daily basis.

Academic stress is defined as a "social fact" that affects the well-being of individuals through the repeated use of technology. It begins with threats that affect interpersonal relationships (Barraza, 2006), generating mental protection from the threat (Benjamin, 1992). Barraza (2006) developed a model to determine stress levels, based on several researches. In this regard, the aforementioned researcher proposed the following dimensions: (1) 'Stressors', are understood as presumed academic activities that produce conflict and, if not properly managed, are a source of stress; (2) 'symptoms of stress', which are associated with exposure to emotional disaster, with indicators of reactions at a post-traumatic level, which could affect the individual for a considerable period of time, generating symptoms such as depression, anxiety, aggressive behavior and conduct, among others, and (3) 'coping', which refers to the quality of response that the individual develops to stressors in order to avoid stages of crisis, so that the subject strives to control his emotions as well as his behavior.

\section{Methodology}

The present research was based on the deductive method, being of basic/substantive type. Due to the nature of the study, a correlational level was chosen because of the need to establish the relationship between the variables 'time management' and 'academic stress'. The design used was non-experimental due to the fact that the variables were not manipulated; the description and explanation of the phenomenon was pursued, so it was a transversal study.

The population was made up of 2200 students from a public university. It was chosen to work with a non-random sample, which was estimated in 328 students of the mentioned institution. For the collection of information, the survey was used as a technique, so two questionnaires were adopted and worked with e1) 'time management' by Robledo (2020), made up of 34 items, and 2) 'academic stress' by Barraza (2007), including 30 items. It is worth mentioning that these were standardized instruments, so it was not necessary to carry out the validity and reliability analysis.

The data were collected through questionnaires, and the information was processed in MS Excel program to elaborate a data matrix. Then, SPSS version 26 software was used to determine the descriptive statistics, as well as the correlation analysis in order to confirm the research hypotheses. 


\section{Results}

According to the data shown in figure 1 for time management and its respective dimensions, it was obtained that $52.1 \%$ considered it adequate; while $43.0 \%$ assumed it to be not enough adequate and only $4.9 \%$, inadequate. With respect to the objectives and priorities dimension, $51.5 \%$ considered it adequate, $41.2 \%$ not enough adequate and only $7.3 \%$ inadequate. For the management tools dimension, $55.5 \%$ of those interviewed considered it adequate, while $39.0 \%$ considered it not enough adequate and 5.5\% inadequate. For the analysis of the Preference for Disorganization dimension, it was found that $60.1 \%$ chose to consider it adequate, $34.1 \%$ as not enough adequate and only $5.8 \%$ as inadequate. Finally, with respect to the control perception dimension, 55.5\% of those surveyed said they found it adequate, while $40.9 \%$ considered it not enough adequate and only $3.7 \%$ chose to consider it inadequate.

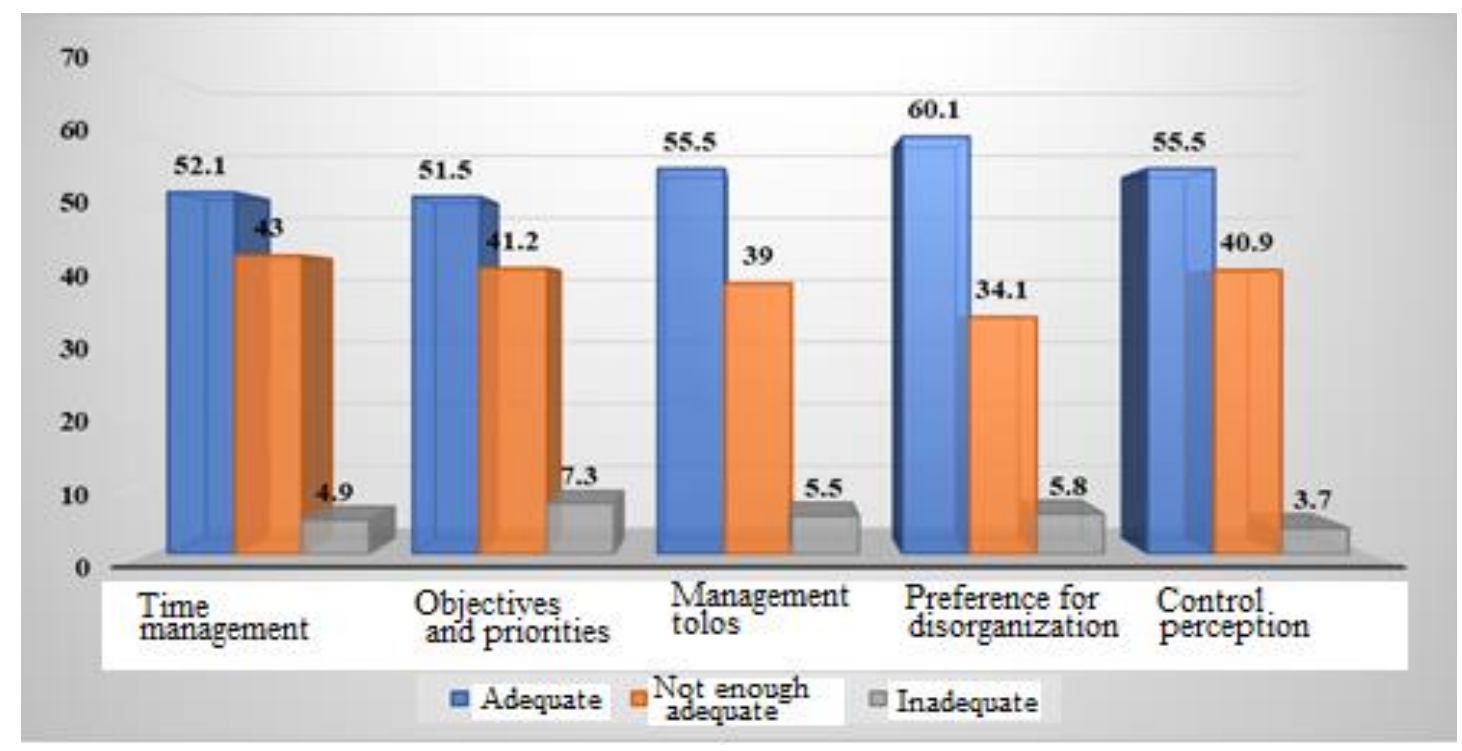

Figure 1. Descriptive analysis of 'time management' and its dimensions

The descriptive analysis of academic stress and its respective dimensions is shown in figure 2, which indicated that $16.8 \%$ of the students surveyed considered it to be high; while $67.7 \%$ of them assumed it to be average and $15.5 \%$ stated that they had a low perception of it. Regarding the stress dimension, $18.9 \%$ considered it high, $64.6 \%$ average and only $16.5 \%$ assumed it was low. For the symptoms dimension, $23.2 \%$ considered it high, $62.5 \%$ average and $14.3 \%$ low. Finally, regarding the coping dimension, out of the total number of people surveyed, $19.2 \%$ considered it high, while a considerable $61.0 \%$ assumed it as average and a not insignificant $19.8 \%$ estimated it as low.

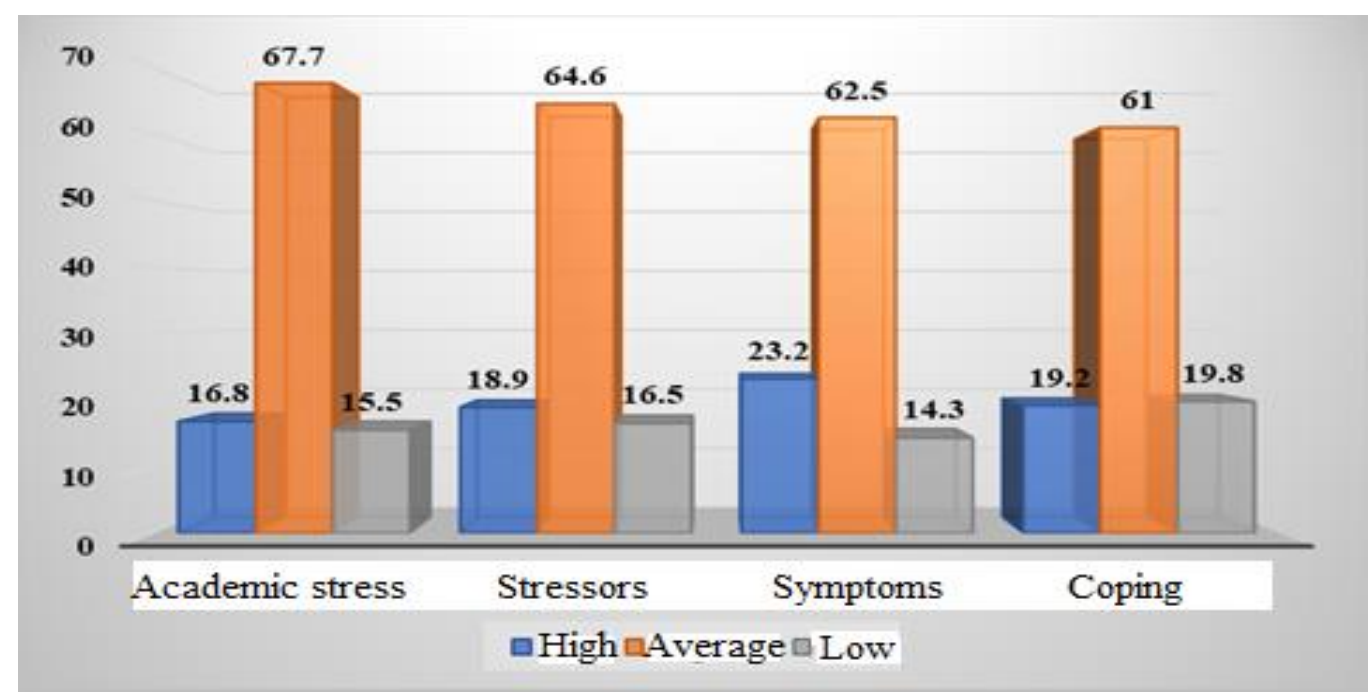

Figure 2. Variable academic stress and dimensions 
Table 1. Correlation analysis between 'time management' and 'academic stress'

\begin{tabular}{lccc}
\hline Variables and/or dimensions & Spearman's Rho & Statistical sig. & N \\
Time management*academic stress &,- 413 &, 000 & 328 \\
Time Management*Stressors &,- 405 &, 000 & 328 \\
Time management*symptoms & -387 &, 000 & 328 \\
Time management*facing &, 286 &, 000 & 328
\end{tabular}

Table 1 shows the corresponding correlation analyses for time management against academic stress which, according to Spearman's rho coefficient $(-0.413)$ with $p<0.000$, there was an inverse and significant relationship between these parameters. It is also worth mentioning that the relationship between time management and the stressors dimension of academic stress was inverse and significant since the value of Spearman's rho coefficient was -0.405. Likewise, the correlation between time management and the symptoms dimension was inverse and significant since Spearman's rho value was -0.387 with a statistical significance of 0.000 . Finally, the correlation between time management and the coping dimension was direct and positive with a Spearman rho value of 0.286 with a statistical significance of 0.000 .

\section{Discussion}

According to the results obtained in relation to time management and its dimensions, the participants in the study generally responded that their management of this parameter was adequate in just over 50\%; these measures were almost similar with respect to objective dimensions and priorities $(51.5 \%)$, management tools $(55.5 \%)$, preferences for disorganization $(60.1 \%)$ and, finally, perception of control $(55.5 \%)$. It should be noted that the highest value was for preferences for disorganization, which would correspond to having an average value of the time management parameter, since this reference is not only a reflection of inadequate planning, but its effect transcends, to some extent, on the other indicators. This aspect is confirmed by the work of Garcia et al. (2004), who reinforced the idea of poor planning in the organization and distribution of time in students, either by ignorance or lack of adequate advice. This generates situations of stress. Likewise, certain similarities are corroborated with what had been reported by Marcén and Martínez (2012), who exposed that more complex curricular experiences tend to increase stress levels and the associated symptomatology in students.

The values obtained for academic stress showed that the students evaluated have assimilated it in a regular or intermediate way, but with a slight upward trend (67.7\%); it should be taken into account that there is a latency of academic stress since $16.8 \%$ declared to have a high level Regarding the dimension of stressors $(67.7 \%)$, symptoms $(62.5 \%)$ and coping $(61 \%)$, in spite of being slightly above the average, it shows that this parameter could, in a not too distant future, develop an upward trend, since the percentage referred to how students assimilate it as low, is slightly below the high level, being this last level one to be taken into account in further studies that seek to investigate more exhaustively the triggers of such perceptions among students. This is related to what was reported by Calderón et al. (2020), who highlighted that if academic stress levels are not managed or treated in time or with professionalism, they could lead to a series of erratic behaviors and even generate suicidal tendencies in students.

With respect to the analysis of correlation between time management and academic stress, the test determined that there was a relationship of inverse order. Such appreciation agrees with the works of Calderón et al. (2020), who when correlating the data of their investigations in relation to the procrastination parameter, found inverse relations of strong levels. It is worth mentioning that it has been determined that time management has kept an inverse relation with the stress dimension, qualifying in the moderate level. This result is aligned to what Herrero et al. (2019) mentioned, who concluded that the management of these parameters allowed to materialize the learning objectives in the studied population. Similarly, the results obtained were close to those of Quiliano and Quiliano (2020) as well as those of Aldana, Isea, and Colina (2020), who demonstrated that stress kept a close inverse association with parameters related to time management in academic life.

With respect to the analysis of correlation of time management with the symptom dimension, the result was an inverse relation qualified as low. It is worth mentioning that it has agreed with what was stated by Palacios, Belito, Bernaola and Capcha (2020) as well as with the results given by Oliveira, Silva, Silva, Moura, Araújo and Silva (2020), who pointed out that procrastination influenced on stress in a strong level; they concluded that the generated 
results could be associated to related factors such as sex, quality of sleep and time at work. Finally, it was possible to demonstrate that there was a direct relationship, at a low level, between time management and the coping dimension. These results were similar to those obtained by Otero et al. (2020) as well as those of Garcia et al. (2019) about stressors and their effects on sleep, anxiety, addictions and suicidal thoughts.

On the other hand, it has been well received in estimating the suggestions of Heo and Han (2018) that online educators might consider and strategically use a variety of basic educational variables that can enhance positive motivation and reduce academic stress among online students. Thus, we estimate that online students are likely to be strongly self-directed and autonomous, increasing their motivation and reducing the level of academic stress in their online education. Therefore, online students would successfully complete their online courses and improve their academic achievement and results as online educators design efficient online courses to be self-directed and student-centered. The latter position is assumed since, due to the pandemic, many students around the globe are now working by remote assistance

\section{References}

Aldana, J., Isea, J., \& Colina, F. (2020). Estrés Académico y Trabajo de Grado en Licenciatura en Educación. Telos, 22(1), 91-105. https://doi.org/10.36390/telos221.07

Barraza, A. (2006). Un modelo conceptual para el estudio del Estrés Académico. Revista Electrónica de Psicología Iztacala, 9(3), 110-129. Retrieved from https://bit.ly/3bexO6F

Barraza, A. (2007). Propiedades psicométricas del Inventario SISCO del estrés académico. Revista de Psicología Científica, 7, 89-93. Retrieved from https://bit.ly/3hKJf8E

Benjamín, S. (1992). El Estrés. México: PressesUniversitairs de France y Publicaciones Cruz.

Bhujade, V. (2017). Depression, anxiety and academic stress among college students: A brief review. Indian Journal of Health \& Wellbeing, 8(7), 748-751.

Broc, M. (2011). Voluntad para estudiar, regulación del esfuerzo, gestión eficaz del tiempo y rendimiento académico en alumnos universitarios. Revista de Investigación Educativa, 29(1), 171-185. Retrieved from https://bit.ly/3bdDfTu

Calderón, C., \& Gustmen, J. (2019). Tutoría y gestión del tiempo en Educación Artística. ArtsEduca, (22), 29-39. Retrieved from https://bit.ly/2QDDePc

Calderón, C., Gustems, J., Calderón, D., \& Pujol, M. (2020). Personalidad adolescente y gestión del tiempo en educación artística. Una investigación aplicada. ArtsEduca, (26), 158-167. https://doi.org/10.6035/Artseduca.2020.26.13

Castro-Rodríguez, Y., Valenzuela-Torres, O., Hinojosa-Añorga, M., \& Piscoche-Rodríguez, C. (2019). Emotional exhaustion in dental students of the National University of San Marcos. Revista Habanera de Ciencias Médicas, 18(1), 150-163. Retrieved from https://bit.ly/32LYSq4

Celis, J., Bustamante, M., Cabrera, D., Cabrera, M., Alarcón, W., \& Monge, E. (2001). Ansiedad y estrés académico en estudiantes de medicina humana del primer y sexto año. Anales de la Facultad de Medicina, 62(1), 25-30. https://doi.org/10.15381/anales.v62i1.4143

Evaristo, T., \& Chein, S. (2015). Estrés y desempeño académico en estudiantes de Odontología. Odontología sanmarquina, 18(1), 23-27. https://doi.org/10.15381/os.v18i1.11336

García-Araiza H., Hernández-Chávez, L., Och-Castillo, J., \& García-Travesi, A. (2019). Estrés universitario en estudiantes de medicina de la Universidad de Quintana Roo. Salud Quintana Roo, 12(41), 13-17. Retrieved from https://bit.ly/3gH8AyV

García-Ros, R., Pérez-Gonzáles, F., \& Hinojosa, E. (2004). Assessing time management skills as an important aspect of student learning. School Psychology Internationa, 25(2), 167-183. http://doi.org/10.1177/0143034304043684

Gregory, A., Buysse, D., Willis, T., Rijsdijk, F., Maughan, B., Rowe, R., Cartwright, S., Barclay, N., \& Eley, T. (2011). Associations between sleep quality and anxiety and depression symptoms in a sample of young adult twins and siblings. Journal of Psychosomatic Research, 71(4), 250-255. https://doi.org/10.1016/j.jpsychores.2011.03.011 
Heo, J., \& Han, S. (2018). Effects of motivation, academic stress and age in predicting self-directed learning readiness (SDLR): Focused on online college students. Education and Information Technologies, 23(1), 61-71. https://doi.org/10.1007/s10639-017-9585-2

Herrero-Blasco, A., Perello-Marin, M., \& Ribes-Giner, G. (2019). La planificación y gestión del tiempo. Competencia transversal con punto de control en la asignatura Dirección de Recursos Humanos en cuarto de ADE. En I Jornada de innovación en docencia universitaria para la dirección de organizaciones públicas y privadas, 93-100. http://doi.org/10.4995/JIDDO2019.2019.10183

Marcén, M., \& Martínez, N. (2012). Gestión eficiente del tiempo de los universitarios: evidencias para estudiantes de primer curso de la Universidad de Zaragoza. Innovar: Revista de Ciencias Administrativas y Sociales, 22(43), 117-130. Retrieved from https://bit.ly/3bi6VyL

Milojevich, H., \& Lukowski, A. (2016). Sleep and mental health in undergraduate students with generally healthy sleep habits. PLoSONE, 11(6), 1-14. https://doi.org/10.1371/journal.pone.0156372

Nadinloyi, K., Hajloo, N., Garamaleki, N., \& Sadeghi, H. (2013). The study efficacy of time management training on increase academic time management of students. Procedia - Social and Behavioral Sciences, (84), 134-138. https://doi.org/10.1016/j.sbspro.2013.06.523

Oliveira, E., Silva, A., Silva, K., Moura, T., Araújo, A., \& Silva, A. (2020). Stress and health risk behaviors among university students. Revista Brasileira de Enfermagen, 73(1), 1-8. http://doi.org/10.1590/0034-7167-2018-0035

Otero-Marrugo, G., Carriazo-Sampayo, G., Támara-Oliver, S., Lacayo-Lepesqueur, M., Torres-Barrios, G., \& Pájaro-Castro, N. (2020). Nivel de estrés académico por evaluación oral y escrita en estudiantes de Medicina de una universidad del Departamento de Sucre. Revista CES Medicina, 34(1), 40-52. http://doi.org/10.21615/cesmedicina.34.1.4

Palacios-Garay, J., Belito Hilario, F., Bernaola-Peña, P., \& Capcha-Carrillo, T. (2020). Procrastinación y estrés en el engagement académico en universitarios. Revista Multi-Ensayos, 45-53. https://doi.org/10.5377/multiensayos.v0i0.9336

Park, S., Park, J., \& Kim, P. (2018). A study on the mediation effects of academic stress on college students' social supports and college adjustment. The Journal of the Korea Contents Association, 18(9), 684-695. https://doi.org/10.5392/JKCA.2018.18.09.684

Quiliano, M., \& Quiliano, M. (2020). Inteligencia emocional y estrés académico en estudiantes de enfermería. Ciencia y Enfermería, 26(3), 1-9. https://doi.org/10.4067/S0717-95532020000100203

Quiroz, D. (2019). Gestión del tiempo, rigor científico y estrés académico en estudiantes modalidad semipresencial, décimo semestre de universidad privada, Pueblo Libre, 2019 [tesis de doctorado. Universidad César Vallejo. Perú]. Retrieved from https://bit.ly/3jxOid0

Reddy, K., Menon, K., \& Thattil, A. (2018). Academic stress and its sources among University students. Biomedical and Pharmacology Journal, 11(1), 531-537. http://doi.org/10.13005/bpj/1404

Ribeiro, F., Mussi, F., Pires, C., Silva, R., Macedo, T., \& Santos, C. (2020). Stress level among undergraduate nursing students related to the training phase and sociodemographic factors. Revista Latino Americana de Enfermagem, 28, 1-11. https://doi.org/10.1590/1518-8345.3036.3209

Roblero, G. (2020). Validación de cuestionario sobre gestión del tiempo en universitarios mexicanos. REDIE: Revista Electrónica de Investigación Educativa, (22), 1-11. https://doi.org/10.24320/redie.2020.22.e01.2136

Sagredo, E., Bizama, M., \& Careaga, M. (2020). Time Management, Co-Teaching and Educational Inclusion. Revista Colombiana de Educación, (78), 343-360. http://doi.org/10.17227/rce.num78-9526

Saleh, D., Camart, N., \& Romo, L. (2017). Predictors of stress in college students. Frontiers in psychology, 8, 19. https://doi.org/10.3389/fpsyg.2017.00019

Zhang, J., \& Zheng, Y. (2017). How do academic stress and leisure activities influence college students' emotional well-being? A daily diary investigation. Journal of adolescence, 60, 114-118. https://doi.org/10.1016/j.adolescence.2017.08.003

Zimmerman, B., \& Martinez, M. (1990). Student differences in self-regulated learning: relating grade, sex, and giftedness to self-efficacy and strategy use. Journal of Educational Psychology, 51-59. https://doi.org/10.1037/0022-0663.82.1.51 


\section{Copyrights}

Copyright for this article is retained by the author(s), with first publication rights granted to the journal.

This is an open-access article distributed under the terms and conditions of the Creative Commons Attribution license (http://creativecommons.org/licenses/by/4.0/). 